\title{
Serotonergic mechanisms responsible for levodopa-induced dyskinesias in Parkinson's disease patients
}

Marios Politis, 1,2 Kit Wu,2 Clare Loane,1,2 David J. Brooks, ${ }^{2,3}$ Lorenzo Kiferle,2 Federico E. Turkheimer,2,4 Peter Bain,2 ${ }^{2}$ Sophie Molloy, ${ }^{2}$ and Paola Piccini²

\begin{abstract}
${ }^{1}$ Neurodegeneration Imaging Group, Department of Clinical Neuroscience, King's College London, London, United Kingdom. ${ }^{2}$ Division of Brain Sciences, Department of Medicine, Imperial College London, London, United Kingdom. ${ }^{3}$ PET Centre, Department of Nuclear Medicine, Aarhus University, Aarhus, Denmark. ${ }^{4}$ Department of Neuroimaging, Institute of Psychiatry, King's College London, London, United Kingdom.
\end{abstract}

\begin{abstract}
Levodopa-induced dyskinesias (LIDs) are the most common and disabling adverse motor effect of therapy in Parkinson's disease (PD) patients. In this study, we investigated serotonergic mechanisms in LIDs development in PD patients using ${ }^{11} \mathrm{C}$-DASB PET to evaluate serotonin terminal function and ${ }^{11} \mathrm{C}$-raclopride PET to evaluate dopamine release. PD patients with LIDs showed relative preservation of serotonergic terminals throughout their disease. Identical levodopa doses induced markedly higher striatal synaptic dopamine concentrations in PD patients with LIDs compared with PD patients with stable responses to levodopa. Oral administration of the serotonin receptor type $1 \mathrm{~A}$ agonist buspirone prior to levodopa reduced levodopaevoked striatal synaptic dopamine increases and attenuated LIDs. PD patients with LIDs that exhibited greater decreases in synaptic dopamine after buspirone pretreatment had higher levels of serotonergic terminal functional integrity. Buspirone-associated modulation of dopamine levels was greater in PD patients with mild LIDs compared with those with more severe LIDs. These findings indicate that striatal serotonergic terminals contribute to LIDs pathophysiology via aberrant processing of exogenous levodopa and release of dopamine as false neurotransmitter in the denervated striatum of PD patients with LIDs. Our results also support the development of selective serotonin receptor type $1 \mathrm{~A}$ agonists for use as antidyskinetic agents in PD.
\end{abstract}

\section{Introduction}

Oral levodopa is still the most effective symptomatic treatment for Parkinson's disease (PD) patients; however, after years of daily exposure, most PD patients develop fluctuating motor responses and troublesome involuntary choreic and dystonic movements, known as levodopa-induced dyskinesias (LIDs) (1). The mechanisms underlying LIDs are currently not fully understood.

In PD patients, the efficacy of exogenous levodopa treatment depends on its ability to raise synaptic levels of dopamine in the denervated striatum. ${ }^{11} \mathrm{C}$-raclopride PET, which detects synaptic dopamine fluxes as changes in $\mathrm{D}_{2}$ receptor availability, has indicated that PD patients with LIDs show larger, but shorterlived, increases in striatal dopamine levels compared with stable responders after clinical doses of levodopa (2).

This aberrant release and clearance of dopamine in PD patients with LIDs could result from involvement of nondopaminergic terminals, as formation, storage, and release of dopamine from exogenous levodopa is known to take place in other monoamine terminals besides the surviving dopaminergic terminals within the striatal tissue, in particular serotonergic terminals (3-5).

Whereas dopamine levels and dopaminergic innervation of the striatum are severely decreased by the time of symptom onset in PD, striatal serotonergic terminal density is only moderately reduced early in the disease and degenerates at a slower pace $(6,7)$. Serotonergic terminals may therefore contribute to the aberrant regulation of motor behavior through mishandling of exogenous levodopa (8-11).

Conflict of interest: The authors have declared that no conflict of interest exists. Citation for this article: J Clin Invest. 2014;124(3):1340-1349. doi:10.1172/JCI71640.
Experimental studies have demonstrated that the presence of levodopa-induced abnormal involuntary movements in rats with 6-hydroxydopamine lesions of the nigrostriatal system is critically dependent on the integrity of serotonergic projections. Removing striatal serotonin (5-HT) afferents, or dampening serotonergic activity with $5-\mathrm{HT}$ receptor type $1 \mathrm{~A}\left(5-\mathrm{HT}_{1 \mathrm{~A}}\right)$ receptor agonists (including buspirone) or 5 -HT receptor type $1 \mathrm{~B}\left(5-\mathrm{HT}_{1 \mathrm{~B}}\right)$ receptor agonists, attenuated abnormal involuntary movements without increasing parkinsonism (12-19). However, this mechanism has not been investigated in vivo in PD patients.

In the present study, we sought to investigate in vivo the role of serotonergic terminal function in the development of LIDs in PD patients. We hypothesized that PD patients with LIDs would show (a) relative preservation of striatal serotonergic terminal function; (b) significantly larger and shorter-term increases in synaptic dopamine levels compared with PD patients with a stable response after levodopa administration; (c) a correlation between severity of LIDs and striatal serotonergic terminal function; and (d) attenuation of striatal synaptic dopamine levels and reduced severity of LIDs when a bolus dose of the $5-\mathrm{HT}_{1 \mathrm{~A}}$ agonist buspirone preceded levodopa administration.

\section{Results}

\section{5-HT $T_{1 A}$ agonist dose-finding study}

We first performed a double-blind randomized dose-finding study with normal controls $(n=12$; Table 1 and Supplemental Table 1; supplemental material available online with this article; doi:10.1172/JCI71640DS1) in order to explore whether the $5-\mathrm{HT}_{1 \mathrm{~A}}$ agonist buspirone influences $\mathrm{D}_{2}$ receptor binding when 
Table 1

Clinical characteristics of PD stable, PD LIDs, and normal control groups

\begin{tabular}{|c|c|c|c|}
\hline & Normal control & PD stable & PD LIDs \\
\hline No. subjects & 12 & 12 & 24 \\
\hline Sex & $10 \mathrm{M} / 2 \mathrm{~F}$ & $10 \mathrm{M} / 2 \mathrm{~F}$ & $19 \mathrm{M} / 5 \mathrm{~F}$ \\
\hline Age (yr) & $63.3 \pm 7.0$ & $66.6 \pm 7.2$ & $65.2 \pm 6.9$ \\
\hline 5-HT LPR polymorphism & $5 \mathrm{~L} / \mathrm{L}, 6 \mathrm{~L} / \mathrm{S}, 1 \mathrm{~S} / \mathrm{S}$ & $6 \mathrm{~L} / \mathrm{L}, 6 \mathrm{~L} / \mathrm{S}, 0 \mathrm{~S} / \mathrm{S}$ & $11 \mathrm{~L} / \mathrm{L}, 11 \mathrm{~L} / \mathrm{S}, 2 \mathrm{~S} / \mathrm{S}$ \\
\hline 5-HT VNTR polymorphism & 6 10/10, 6 12/12 & $710 / 10,5$ 12/12 & $1310 / 10,1112 / 12$ \\
\hline Disease duration $(\mathrm{yr})^{\mathrm{A}}$ & - & $5.6 \pm 3.5$ & $11.8 \pm 4.3^{B}$ \\
\hline Tremor-dominant/akinetic-rigi & - & $4: 8$ & $7: 17$ \\
\hline H\&Y, OFF medication & - & $2.4 \pm 0.8$ & $3.2 \pm 0.8^{c}$ \\
\hline UPDRS-III, OFF medication & - & $28.5 \pm 13.1$ & $42.1 \pm 9.4^{B}$ \\
\hline On PD medication duration (yr & - & $3.9 \pm 3.6$ & $10.2 \pm 3.8^{B}$ \\
\hline On DAg duration (yr) & - & $2.3 \pm 4.1$ & $6.8 \pm 2.2^{\mathrm{D}}$ \\
\hline On levodopa duration (yr) & - & $2.1 \pm 1.2$ & $8.1 \pm 3.8^{B}$ \\
\hline Daily $L D_{\text {total }}(\mathrm{mg})$ & - & $443 \pm 98$ & $1,043 \pm 544$ \\
\hline Daily LED ${ }_{\text {DAg }}(\mathrm{mg})$ & - & $95 \pm 115$ & $166 \pm 176$ \\
\hline Daily LED & - & $349 \pm 115$ & $877 \pm 399$ \\
\hline Lifetime LED total $(\mathrm{g})$ & - & $404 \pm 431$ & $2,111 \pm 1,200^{B}$ \\
\hline Lifetime $\mathrm{LED}_{\mathrm{DAg}}(\mathrm{g} \pm \mathrm{SD})$ & - & $203 \pm 451$ & $452 \pm 348^{c}$ \\
\hline Lifetime LED levodopa $(g \pm S D)$ & - & $201 \pm 159$ & $1,659 \pm 1,060^{\mathrm{B}}$ \\
\hline MMSE & $29.4 \pm 0.7$ & $29.0 \pm 1.6$ & $28.7 \pm 2.2$ \\
\hline BDI-II & $3.1 \pm 2.6$ & $11.8 \pm 4.8^{D}$ & $11.0 \pm 5.6^{\mathrm{D}}$ \\
\hline HRSD & $2.6 \pm 2.7$ & $8.3 \pm 3.5^{C}$ & $9.5 \pm 5.2^{D}$ \\
\hline BMI & $29.2 \pm 5.4$ & $25.7 \pm 3.1$ & $25.5 \pm 4.1$ \\
\hline
\end{tabular}

Data represent mean \pm SD. For LED calculation formulas, see Supplemental Tables 12-14. H\&Y, Hoehn and Yahr; DAg, dopamine agonist; MMSE, Mini Mental State Examination; BDI-II, Beck Depression Inventory; HRSD, Hamilton Rating Scale for Depression. AFrom time of first appearance of $P D$ motor symptoms. $B P<0.001 .{ }^{C} P<0.05$. $D P<0.01$.

the dopaminergic system is intact and to establish the adverse event profile with 2 different doses (low and high) of the drug. There were no significant differences in nondisplaceable binding potential $\left(\mathrm{BP}_{\mathrm{ND}}\right)$ of caudate and putamen ${ }^{11} \mathrm{C}$-raclopride (a marker of $\mathrm{D}_{2}$ receptor availability) at baseline and after exposure to a 0.20 or $0.35 \mathrm{mg} / \mathrm{kg}$ bolus dose of buspirone $(P>0.1)$ or between the 2 subgroups $(P>0.1$; Supplemental Figure 1 and Supplemental Tables 2 and 3). 6 of 12 subjects (50\%) reported an adverse event of mild intensity. There were no differences in the frequency or intensity of side effects reported by the 2 dose groups (Supplemental Table 4). Given these findings in normal controls, we decided to use a $0.35 \mathrm{mg} / \mathrm{kg}$ buspirone dose in the PD trial in order to achieve a higher blockade of serotonergic terminal neurotransmission and attenuate excessive dopamine release from these terminals, thus reducing the severity of LIDs.

\section{$P E T$ and clinical assessments of $P D$ patients with LIDs}

Striatal serotonergic terminal functional integrity was assessed with the 5-HT transporter (SERT) marker ${ }^{11} \mathrm{C}$-DASB PET in PD patients and normal controls. Estimated changes of striatal dopamine levels were measured after ${ }^{11} \mathrm{C}$-raclopride PET competition studies with levodopa and buspirone. Clinical evaluations of peak-dose LIDs were assessed using Abnormal Involuntary Movement Scale
(AIMS) rating scores, and PD motor symptoms were assessed using the Unified PD Rating Scale Part-III (UPDRS-III). All PET and clinical assessments were performed in a double-blind randomized fashion (Figure 1). Assessment of SERT function $\left({ }^{11} \mathrm{C}-D A S B P E T\right)$. No significant differences were found in caudate and putamen ${ }^{11} \mathrm{C}$-DASB $\mathrm{BP}_{\mathrm{ND}}$ between the PD patients with LIDs (referred to herein as PD LIDs) and those with a stable response to levodopa (PD stable) (Figure 2A and Supplemental Table 5).

Assessment of synaptic dopamine levels $\left({ }^{11} \mathrm{C}\right.$-raclopride PET). Administration of levodopa significantly reduced mean caudate and putamen ${ }^{11} \mathrm{C}$-raclopride $\mathrm{BP}_{\mathrm{ND}}$ in the $\mathrm{PD}$ stable group (caudate, $6 \%$ decrease from baseline; putamen, $8 \%$ decrease). There was no effect of buspirone pretreatment on striatal ${ }^{11} \mathrm{C}$-raclopride $\mathrm{BP}_{\mathrm{ND}}$ compared with levodopa challenge alone in the PD stable group (Figure 2B and Supplemental Table 6).

After levodopa challenge, PD LIDs patients showed significantly greater reductions of mean caudate and putamen ${ }^{11} \mathrm{C}$-raclopride $\mathrm{BP}_{\mathrm{ND}}$ compared with PD stable patients (caudate, $13 \%$ decrease from baseline; putamen, $17 \%$ decrease). Buspirone pretreatment significantly increased striatal ${ }^{11} \mathrm{C}$-raclopride $\mathrm{BP}_{\mathrm{ND}}$ compared with levodopa alone in $\mathrm{PD}$ LIDs patients (caudate, 9\% decrease from baseline; putamen, 11\% decrease; Figure 2C and Supplemental Table 7).

Clinical assessments and correlations. The PD LIDs group was clinically more advanced, and these patients had received larger doses of dopaminergic medications for a longer duration (Table 1).

In the PD LIDs group over a 150-minute observational period, buspirone pretreatment significantly reduced AIMS scores com-
PET imaging studies to assess dopamine release

\begin{tabular}{|c|c|c|}
\hline${ }^{11} \mathrm{C}$-Raclopride PET scan \\
Baseline \\
OFF medication
\end{tabular}$\quad \begin{gathered}{ }^{11} \mathrm{C} \text {-Raclopride PET scan } \\
\text { levodopa challenge } \\
60 \text { min before PET }\end{gathered} \quad \begin{gathered}{ }^{11} \mathrm{C} \text {-Raclopride PET scan } \\
5-\mathrm{HT}_{1 \mathrm{~A}} \text { agonist \& levodopa challenge } \\
75 \& 60 \mathrm{~min} \text { before PET, respectively }\end{gathered}$

PET imaging studies to assess serotonergic terminal integrity

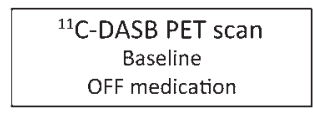

Clinical assessments

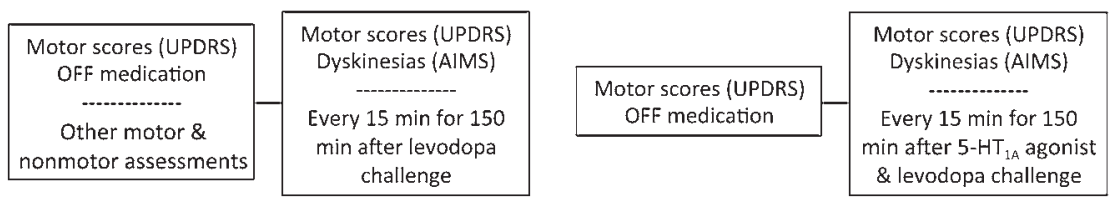

Figure 1

PET imaging and clinical studies. 

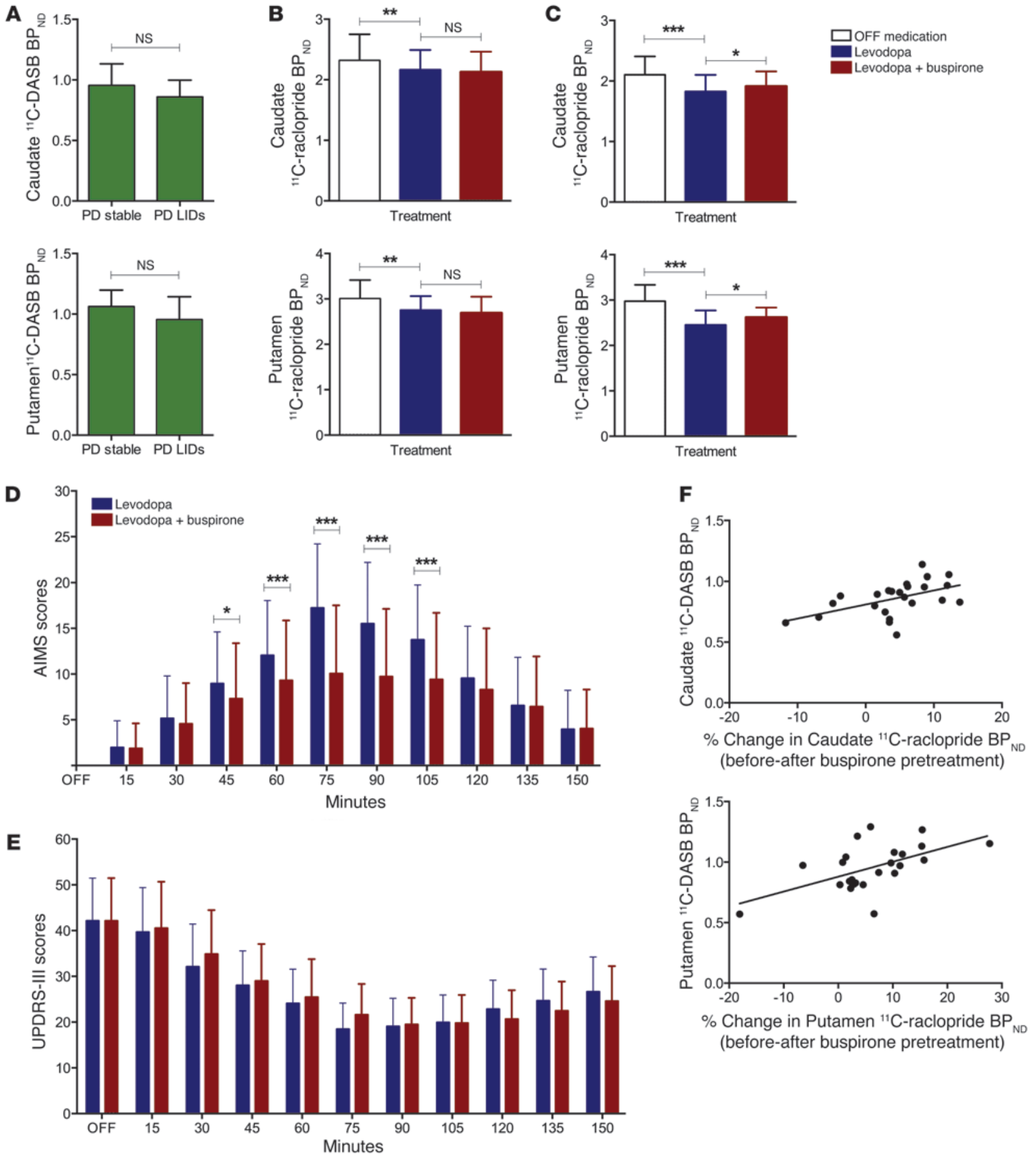

Figure 2

${ }^{11} \mathrm{C}$-DASB and ${ }^{11} \mathrm{C}$-raclopride PET competition studies with levodopa and buspirone, and clinical assessments, in PD stable $(n=12)$ and PD LIDs $(n=24)$ patients. (A) No significant differences in caudate and putamen mean ${ }^{11} \mathrm{C}$-DASB BP ${ }_{\mathrm{ND}}$ values between the PD stable and PD LIDs groups. (B and C) ${ }^{11} \mathrm{C}$-raclopride PET competition studies in the PD stable (B) and PD LIDs (C) groups, showing mean ${ }^{11} \mathrm{C}$-raclopride $\mathrm{BP}$ ND values OFF medication and after challenge with levodopa, with or without $0.35 \mathrm{mg} / \mathrm{kg}$ buspirone pretreatment. (D and E) Mean AIMS (D) and UPDRS-III (E) scores in PD LIDs patients recorded while OFF medication and for 150 minutes after levodopa administration, with or without $0.35 \mathrm{mg} / \mathrm{kg}$ buspirone pretreatment. $(\mathbf{F})$ Correlations between higher caudate and putamen ${ }^{11} \mathrm{C}-\mathrm{DASB}$ BP $\mathrm{ND}_{\mathrm{N}}$ values and higher decreases in percent reductions in caudate and putamen ${ }^{11} \mathrm{C}$-raclopride $\mathrm{BP}_{\mathrm{ND}}$ after buspirone pretreatment in PD LIDs patients. Data represent mean $+\mathrm{SD}$. ${ }^{\star} P<0.05,{ }^{\star \star} P<0.01,{ }^{\star \star \star} P<0.001$. 


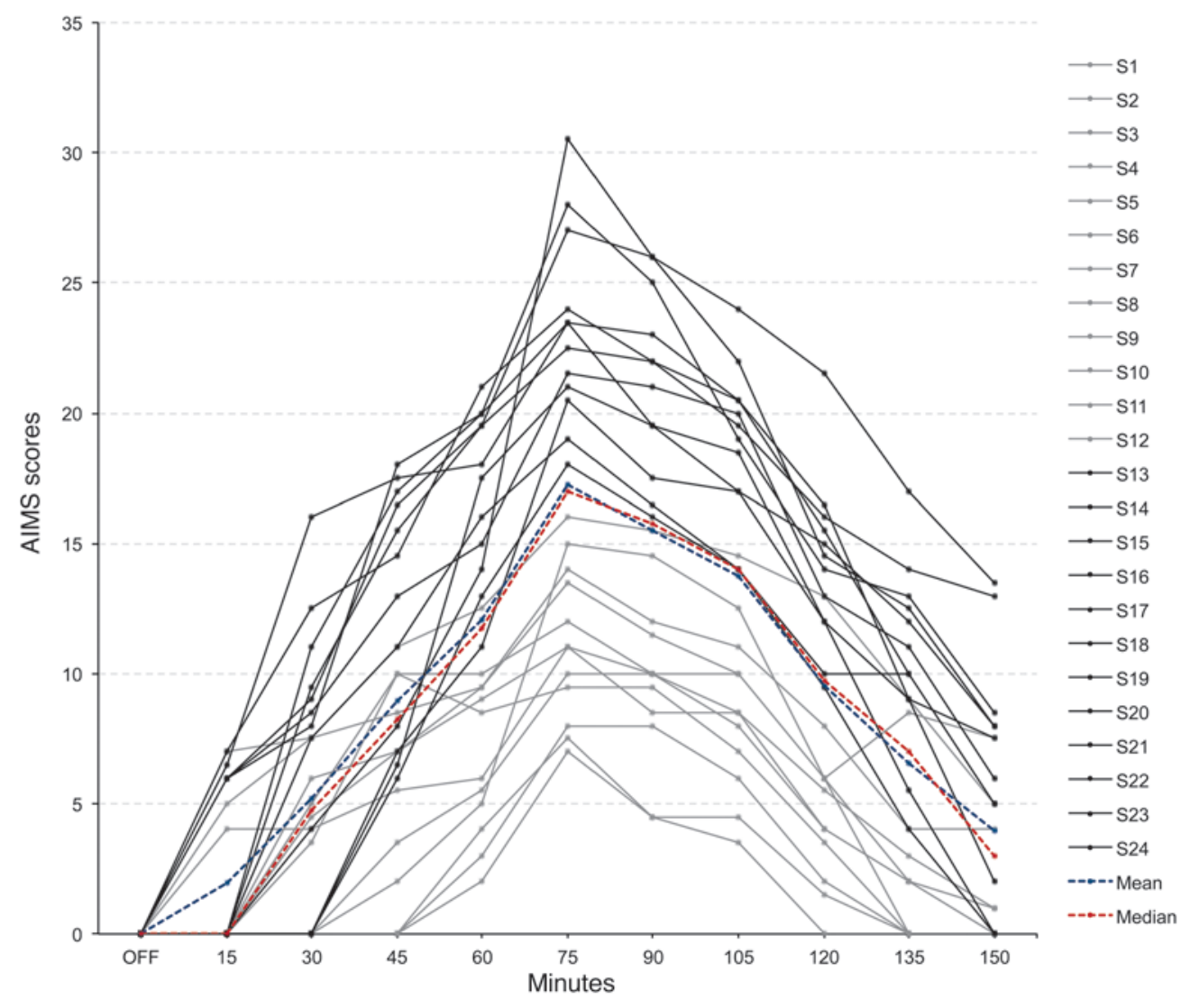

\section{Figure 3}

Individual AIMS scores for PD patients with LIDs $(n=24)$ after levodopa administration. 12 subjects were below (gray lines) and 12 above (black lines) the discriminating mean (blue dotted line) and median (red dotted line) cutoff for categorization into PD MM LIDs (S1-S12) and PD MS LIDs (S13-S24) groups. pared with levodopa challenge alone $\left(F_{(1,23)}=9.96 ; P<0.01\right)$. PD LIDs patients showed significantly decreased AIMS scores at 45 minutes $(P<0.05)$ and $60-105$ minutes $(P<0.001)$ with buspirone pretreatment compared with levodopa challenge alone. The mean reduction in peak AIMS score was around one-third (Figure 2D). We found no effect of buspirone pretreatment on UPDRS-III scores compared with levodopa alone in either the PD stable $\left(F_{(1,23)}=0.44\right.$; $P>0.1)$ or the PD LIDs group $\left(F_{(1,23)}=0.48 ; P>0.1\right)$ (Figure $2 \mathrm{E}$ ). 14 of 36 PD subjects (39\%) reported at least 1 mild adverse event associated with buspirone (Supplemental Table 8).

After levodopa administration, higher maximum AIMS scores over a 150-minute period correlated with higher percentage reductions in putamen ${ }^{11} \mathrm{C}$-raclopride $\mathrm{BP}_{\mathrm{ND}}$ in the $\mathrm{PD}$ LIDs group $(r=0.58 ; P<0.01$; Supplemental Figure 2).

With buspirone pretreatment, greater decreases in caudate $(r=0.52 ; P<0.01)$ and putamen $(r=0.57 ; P<0.01){ }^{11} \mathrm{C}$-raclopride $\mathrm{BP}_{\mathrm{ND}}$ percentage reductions correlated with higher ${ }^{11} \mathrm{C}$-DASB $\mathrm{BP}_{\mathrm{ND}}$ in the PD LIDs group (Figure $2 \mathrm{~F}$ ).

\section{Post-hoc analysis according to LIDs severity}

We wanted to explore whether the serotonergic mechanisms influence the severity of LIDs. The 24 PD LIDs patients were further divided into 2 subgroups, depending on whether their LIDs severity was above or below the mean and median LIDs severity assessed over 150 minutes after levodopa administration (Figure 3). 12 PD LIDs patients were classified as having mild-moderate LIDs (referred to herein as PD MM LIDs), and 12 were classified as having moderate-severe LIDs (PD MS LIDs). The PD MS LIDs group had longer disease duration, was more clinically affected, and had received levodopa treatment for a longer period compared with the PD MM LIDs group (Table 2).

Assessment of SERT function ( ${ }^{11} C-D A S B$ PET). PD MM LIDs and PD MS LIDs patients showed significant reductions in caudate and putamen ${ }^{11} \mathrm{C}-\mathrm{DASB} \mathrm{BP}_{\mathrm{ND}}$ compared with normal controls, but no significant differences between the 2 subgroups (Figure 4A and Supplemental Table 9).

Assessment of synaptic dopamine levels $\left({ }^{11} \mathrm{C}\right.$-raclopride PET). In the PD MM LIDs group, levodopa administration significantly reduced mean caudate and putamen ${ }^{11} \mathrm{C}$-raclopride $\mathrm{BP}_{\mathrm{ND}}$ (caudate, $12 \%$ decrease from baseline; putamen, $15 \%$ decrease; Figure 4B). In the same group, buspirone pretreatment significantly increased striatal ${ }^{11} \mathrm{C}$-raclopride $\mathrm{BP}_{\mathrm{ND}}$ compared with levodopa alone (caudate, $6 \%$ decrease from baseline; putamen, $7 \%$ decrease; Figure $4 \mathrm{~B}$ and Supplemental Table 10).

PD MS LIDs patients showed even more significant reductions in mean caudate and putamen ${ }^{11} \mathrm{C}$-raclopride $\mathrm{BP}_{\mathrm{ND}}$ after levodopa challenge (caudate, 14\% decrease from baseline; putamen, 19\% decrease; Figure 4C). However, there was no effect of buspirone pretreatment on striatal ${ }^{11} \mathrm{C}$-raclopride $\mathrm{BP}_{\mathrm{ND}}$ compared with levodopa alone (Figure 4C and Supplemental Table 11).

Clinical assessments and correlations. Over a 150-minute observational period, buspirone pretreatment significantly reduced AIMS scores compared with levodopa challenge alone in the PD MM LIDs group $\left(F_{(1,11)}=17.38 ; P<0.01\right)$. PD MM LIDs patients showed significantly decreased AIMS scores after levodopa administration with buspirone pretreatment at 45 minutes $(P<0.05), 60$ minutes $(P<0.01)$, and $75-105$ minutes $(P<0.001)$ compared with levodopa alone. The mean reduction in peak AIMS score was around $50 \%$ 
Table 2

Clinical characteristics of PD MM LIDs and PD MS LIDs groups

\begin{tabular}{|c|c|c|}
\hline & PD MM LIDs & PD MS LIDs \\
\hline No. subjects & 12 & 12 \\
\hline Sex & $9 M / 3 F$ & $10 \mathrm{M} / 2 \mathrm{~F}$ \\
\hline Age (yr) & $64.3 \pm 5.7$ & $66.1 \pm 8.3$ \\
\hline 5-HT LPR polymorphism & $6 \mathrm{~L} / \mathrm{L}, 5 \mathrm{~L} / \mathrm{S}, 1 \mathrm{~S} / \mathrm{S}$ & $5 \mathrm{~L} / \mathrm{L}, 6 \mathrm{~L} / \mathrm{S}, 1 \mathrm{~S} / \mathrm{S}$ \\
\hline 5-HT VNTR polymorphism & $610 / 10,612 / 12$ & $710 / 10,512 / 12$ \\
\hline Disease duration $(\mathrm{yr})^{\mathrm{A}}$ & $10.1 \pm 3.4$ & $13.4 \pm 4.6^{B}$ \\
\hline Tremor-dominant/akinetic-rigid & $4: 8$ & $3: 9$ \\
\hline H\&Y, OFF medication & $2.5 \pm 0.7$ & $3.5 \pm 0.9^{B}$ \\
\hline UPDRS-III, OFF medication & $37.8 \pm 7.8$ & $46.5 \pm 9.0^{B}$ \\
\hline On PD medication duration (yr) & $8.4 \pm 2.9$ & $12.1 \pm 3.8^{\mathrm{C}}$ \\
\hline On DAg duration (yr) & $6.6 \pm 1.8$ & $7.0 \pm 2.7$ \\
\hline On levodopa duration (yr) & $6.6 \pm 4.0$ & $9.5 \pm 3.1^{c}$ \\
\hline Daily $L_{E D} D_{\text {total }}(\mathrm{mg})$ & $1,053 \pm 338$ & $1,033 \pm 712$ \\
\hline Daily LED $D_{\text {DAg }}(\mathrm{mg})$ & $173 \pm 73$ & $159 \pm 244$ \\
\hline Daily LED levodopa $(\mathrm{mg})$ & $880 \pm 306$ & $874 \pm 488$ \\
\hline Lifetime LED $_{\text {total }}(\mathrm{g})$ & $1,911 \pm 1,043$ & $2,311 \pm 1,354$ \\
\hline Lifetime $\mathrm{LED}_{\mathrm{DAg}}(\mathrm{g} \pm \mathrm{SD})$ & $519 \pm 251$ & $384 \pm 425$ \\
\hline Lifetime LED levodopa $(\mathrm{g} \pm \mathrm{SD})$ & $1,391 \pm 1,120$ & $1,927 \pm 969$ \\
\hline MMSE & $29.3 \pm 0.8$ & $28.1 \pm 2.9$ \\
\hline BDI-II & $11.4 \pm 6.3$ & $10.7 \pm 5.2$ \\
\hline HRSD & $9.2 \pm 5.7$ & $9.9 \pm 4.9$ \\
\hline BMI & $25.8 \pm 4.2$ & $25.3 \pm 4.1$ \\
\hline
\end{tabular}

Data represent mean \pm SD. For LED calculation formulas, see Supplemental Tables 12-14. H\&Y, Hoehn and Yahr; DAg, dopamine agonist; MMSE, Mini Mental State Examination; BDI-II, Beck Depression Inventory; HRSD, Hamilton Rating Scale for Depression. AFrom time of first appearance of $P D$ motor symptoms. ${ }^{B} P<0.05 .{ }^{C} P<0.01$.

(Figure 4D). Although PD MS LIDs patients showed a mean 25\% reduction in AIMS scores with buspirone pretreatment, this effect did not reach significance $\left(F_{(1,11)}=2.97 ; P>0.1\right.$; Figure $\left.4 \mathrm{E}\right)$.

We found no effect of buspirone pretreatment on UPDRS-III scores compared with levodopa alone in either the PD MM LIDs group $\left(F_{(1,11)}=0.62 ; P>0.1\right.$; Figure $\left.4 \mathrm{~F}\right)$ or the PD MS LIDs group $\left(F_{(1,11)}=0.17 ; P>0.1 ;\right.$ Figure $\left.4 \mathrm{G}\right)$.

Higher putamen ${ }^{11} \mathrm{C}$-DASB $\mathrm{BP}_{\mathrm{ND}}$ significantly correlated with maximum $(r=0.76, P<0.01)$ and average $(r=0.78, P<0.01)$ AIMS scores during a 150-minute period after levodopa challenge in the PD MM LIDs group (Figure 5A). Although a similar correlation between ${ }^{11} \mathrm{C}$-DASB $\mathrm{BP}_{\mathrm{ND}}$ and AIMS scores was observed for caudate, $P$ values did not survive correction for multiple comparisons (Supplemental Figures 3 and 4).

After buspirone pretreatment, greater decreases in putamen ${ }^{11} \mathrm{C}$-raclopride $\mathrm{BP}_{\mathrm{ND}}$ percentage reductions (corrected for $\left.{ }^{11} \mathrm{C}-\mathrm{DASB} \mathrm{BP}_{\mathrm{ND}}\right)$ correlated with higher improvements in maximum $(r=0.64, P<0.05)$ and average $(r=0.72, P<0.01)$ AIMS scores during the 150 -minute observational period in the PD MM LIDs group (Figure 5B).

\section{Discussion}

Our findings demonstrated in vivo in PD patients that striatal serotonergic terminals play a significant role in the pathophysiology of patient peak-dose LIDs. The present study supported previous experimental findings on animal models of PD (12-19) and translated them to humans. Using a series of PET imaging assessments with radioligand markers of serotonergic $\left({ }^{11} \mathrm{C}-\mathrm{DASB}\right)$ and dopaminergic ( ${ }^{11} \mathrm{C}$-raclopride) function (Figure 6$)$, we showed that striatal serotonergic terminals contributed to abnormal levodopa-induced short-term increases in synaptic dopamine levels in PD patients with LIDs and that the dampening of the activity of these serotonergic terminals via a $5-\mathrm{HT}_{1 \mathrm{~A}}$ agonist restored synaptic dopamine to levels similar to those observed in PD stable patients and improved LIDs.

We also confirmed that PD LIDs patients showed greater increases in striatal dopamine levels than PD stable patients after levodopa administration (2) and further showed that increased synaptic levels of dopamine correlated with severity of LIDs. Preclinical studies have shown that serotonergic terminals are able to convert exogenous levodopa to dopamine, store and release this into the extracellular space $(3-5,10)$. Serotonergic terminals can also take up dopamine from the extracellular space via SERT (8, $9,11)$. Such a mechanism becomes relevant to PD when striatal serotonergic terminals are still relatively preserved or less damaged than degenerating dopaminergic terminals and can therefore influence synaptic dopamine levels.

5-HT binding was found to be significantly reduced in all the PD subgroups compared with controls, in line with previous reports $(6,7)$. However, patients of the PD LIDs group showed relative preservation of serotonergic terminal function compared with the PD stable group. Previous PET imaging work from our group has indicated that in patients with advanced $\mathrm{PD}, 5-\mathrm{HT}$ binding in the putamen is reduced by $30 \%$ (7), significantly less than the severe reductions (>75\%) of dopaminergic function (20). Our PD LIDs cohort was an advanced group (>10 years disease duration), compared with our PD stable group with earlier disease $(<6$ years disease duration). This situation is the reverse of that with the dopaminergic system, as PD patients with motor complications including LIDs show a greater loss of presynaptic dopaminergic terminals in putamen compared with PD patients with stable response to levodopa (21). Slower degeneration of serotonergic (versus dopaminergic) terminals as PD progresses could be a risk factor for occurrence of LIDs. It remains unclear why advanced PD patients with LIDs should have relatively preserved serotonergic terminals; this phenomenon could be due to upregulation of SERT or interactions with other neuronal systems, such as the glutamatergic system.

The role of serotonergic terminals in the aberrant release of striatal dopamine and in promoting the development of LIDs is supported by the observation that higher striatal 5-HT binding correlated with decreases in striatal dopamine levels after pretreatment with a high bolus dose $(0.35 \mathrm{mg} / \mathrm{kg})$ of the $5-\mathrm{HT}_{1 \mathrm{~A}}$ agonist buspirone 15 minutes prior to levodopa administration. Moreover, the same dose of buspirone was able to significantly attenuate the high levodopa-induced striatal dopamine levels and LIDs during their peak (45-105 minutes after levodopa administration). ${ }^{11} \mathrm{C}$-raclopride $\mathrm{BP}_{\mathrm{ND}}$ was reduced when synaptic dopamine levels rose, due to mutual competition for $\mathrm{D}_{2}$ sites. Reductions of ${ }^{11} \mathrm{C}$-raclopride $\mathrm{BP}_{\mathrm{ND}}$ after levodopa fell from $13 \%$ to $9 \%$ in the caudate and from $17 \%$ to $11 \%$ in the putamen when buspirone preceded levodopa. Buspirone pretreatment did not affect levodopa-induced motor performance improvement, as assessed by UPDRS-III motor scores, in the PD patients.

We chose to use buspirone in this study because it is the only $5-\mathrm{HT}_{1 \mathrm{~A}}$ agonist medically licensed in United Kingdom. Buspirone has a complex mechanism of action, acting as a weak $\mathrm{D}_{2}$ receptor antagonist as well as an $\alpha 1$ adrenergic receptor and $5-\mathrm{HT}_{1 \mathrm{~A}}$ agonist. It is probable that a dose of $0.35 \mathrm{mg} / \mathrm{kg}$ does not directly influence $\mathrm{D}_{2}$ receptors, as ${ }^{11} \mathrm{C}$-raclopride uptake was unchanged by buspirone in our dose-finding study in a group of normal con- 


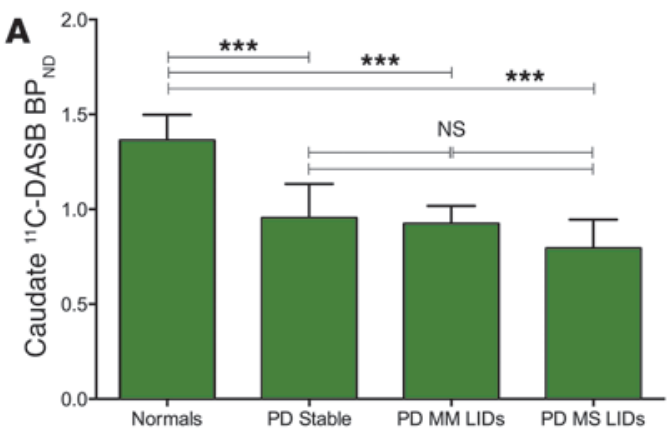

B
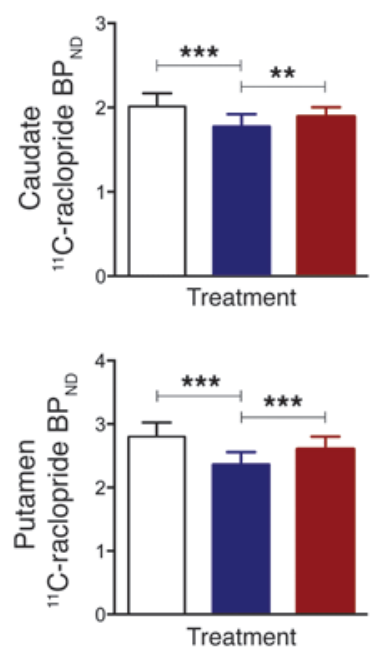

C
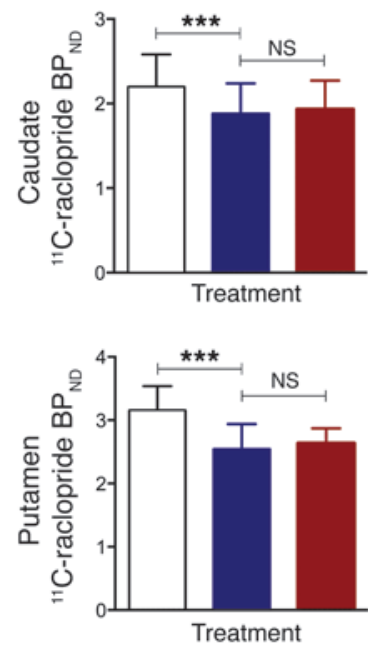

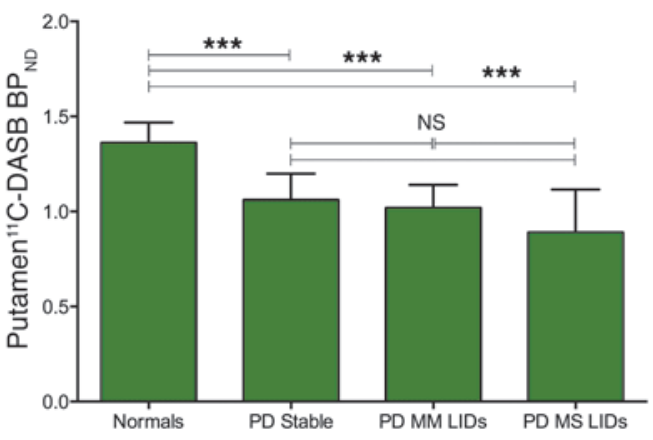

$\square$ OFF medication

Levodopa

Levodopa + buspirone

$\mathbf{F}$
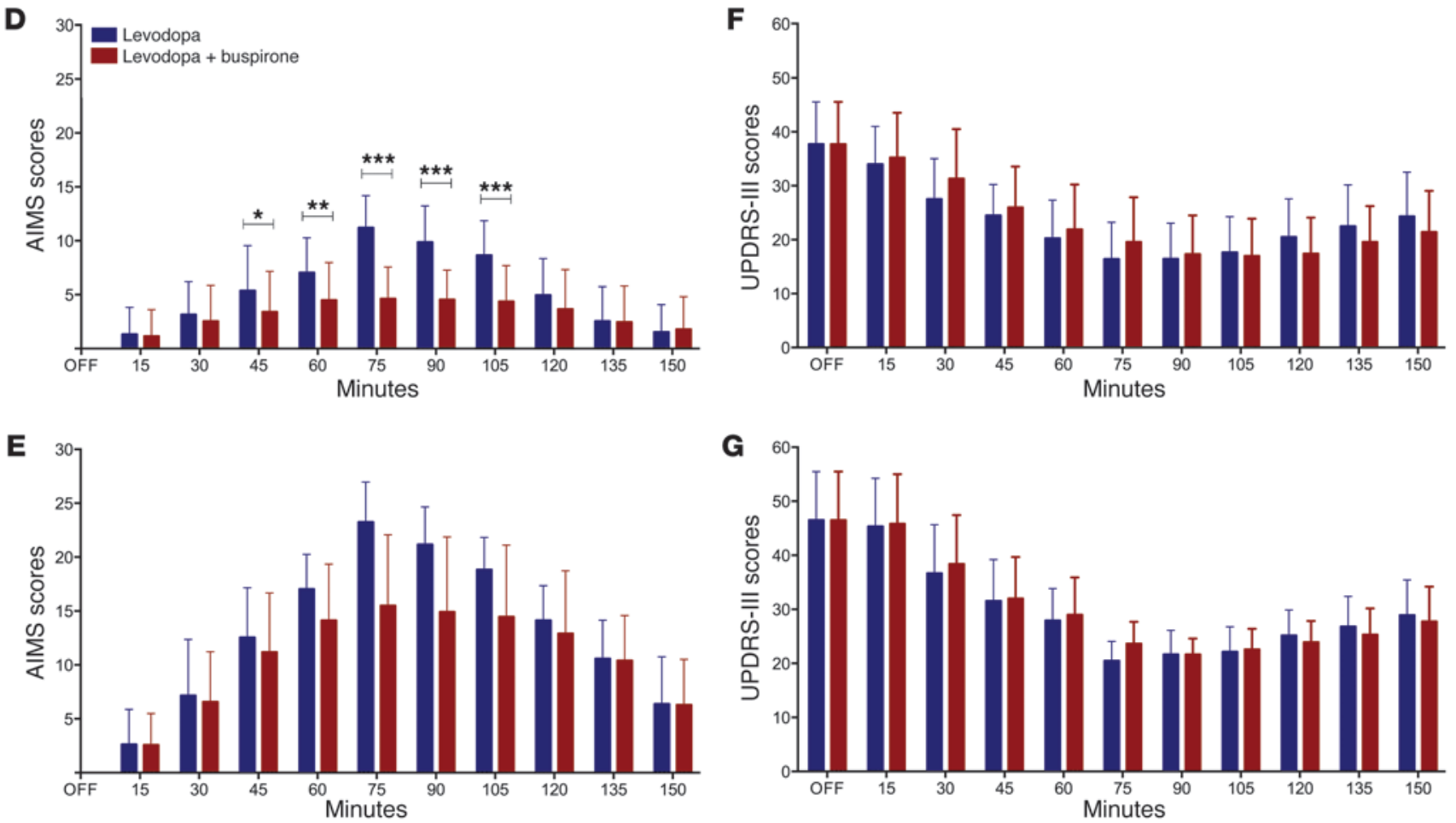

Figure 4

${ }^{11} \mathrm{C}$-DASB and ${ }^{11} \mathrm{C}$-raclopride PET competition studies with levodopa and buspirone, and clinical assessments, in PD MM LIDs and PD MS LIDs

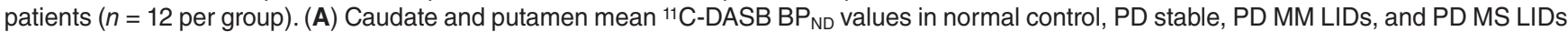
groups. (B and C) ${ }^{11} \mathrm{C}$-raclopride PET competition studies in PD MM LIDs (B) and PD MS LIDs (C) groups showing mean ${ }^{11} \mathrm{C}$-raclopride $\mathrm{BP}{ }_{\mathrm{ND}}$ values OFF medication and after levodopa challenge, with or without $0.35 \mathrm{mg} / \mathrm{kg}$ buspirone pretreatment. (D-G) Mean AIMS (D and E) and UPDRS-III ( $\mathbf{F}$ and $\mathbf{G}$ ) scores in PD MM LIDs ( $\mathbf{D}$ and $\mathbf{F}$ ) and PD MS LIDs ( $\mathbf{E}$ and $\mathbf{G}$ ) patients OFF medication and for 150 minutes after levodopa challenge, with or without $0.35 \mathrm{mg} / \mathrm{kg}$ buspirone pretreatment. Data represent mean $+\mathrm{SD}$. ${ }^{*} P<0.05,{ }^{* *} P<0.01,{ }^{* * *} P<0.001$. 

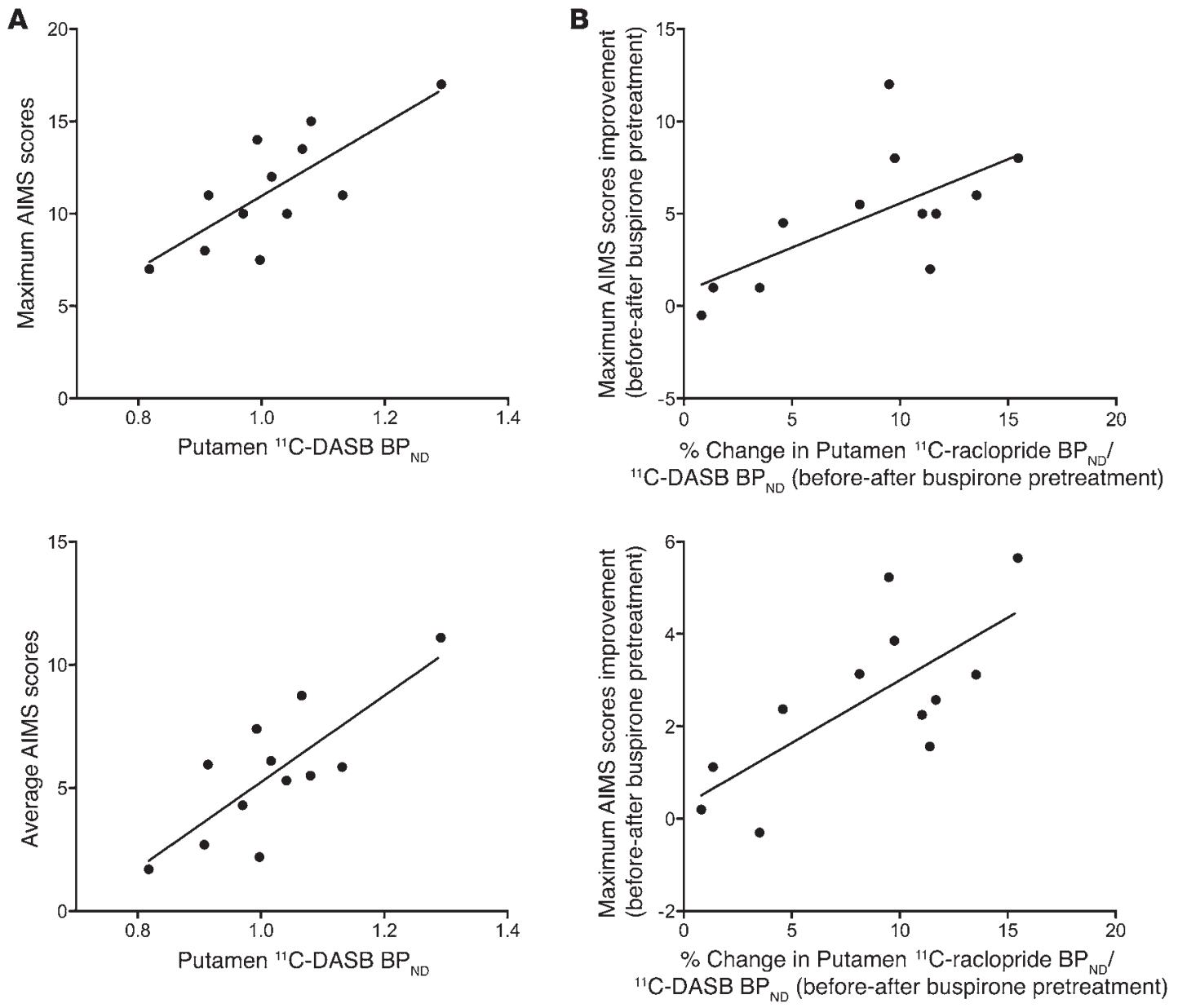

Figure 5

Significant correlations between clinical and PET imaging data in the PD MM LIDs group $(n=12)$. (A) Higher putamen ${ }^{11} \mathrm{C}$-DASB BP ND values correlated with higher maximum and average AIMS scores during the 150-minute period after levodopa administration. (B) Higher decreases in percent reductions of putamen ${ }^{11} \mathrm{C}$-raclopride $\mathrm{BP}_{\mathrm{ND}}$ values (corrected for ${ }^{11} \mathrm{C}$-DASB $\mathrm{BP}_{\mathrm{ND}}$ values) correlated with higher maximum and average improvements in AIMS scores during the 150-minute period after buspirone pretreatment.

trols. Its major action appears to be reduction of dopamine release after levodopa by dampening serotonergic neuronal firing via its agonism at 5- $\mathrm{HT}_{1 \mathrm{~A}}$ sites, thus attenuating peak-dose LIDs. Pretreatment with buspirone could be inducing a placebo effect, but this is unlikely, as dopamine release would be expected to increase, rather than decrease as shown here. Striatal dopamine synaptic levels after levodopa administration were not influenced by buspirone pretreatment in the PD stable patient group.

Our results are in line with experimental studies showing that $5-\mathrm{HT}_{1 \mathrm{~A}}$ agonists, including buspirone, are able to reduce or prevent the development of levodopa-induced abnormal involuntary movements in animal models of PD (12-19). Studies using dyskinetic rats have shown that levodopa-induced abnormal involuntary movements in rats positively correlate with levels of SERT, but not with levels of dopamine transporter, in the striatum (22). In the present study, we were unable to demonstrate a correlation between SERT binding and the severity of LIDs across the entire PD cohort. Therefore, we proceeded to explore whether the serotonergic mechanisms in the development of LIDs are expressed differently according to their severity.
In the PD MM LIDs group, striatal SERT binding correlated with severity of LIDs, in agreement with animal studies (22). This correlation was not present in the PD MS LIDs group. The effect of buspirone was also more robust in the PD MM LIDs group and resulted in greater reductions of dopamine levels in both caudate (from $12 \%$ to $6 \%$ ) and putamen (from $15 \%$ to $7 \%$ ), bringing dopamine release down to the levels observed in the PD stable group. In the PD MM LIDs group, buspirone evoked decreases in dopamine release (per 5-HT binding) that correlated with improvements in dyskinesia scores, indicative of an association between excessive dopamine release from the serotonergic terminals and dyskinesia development. PD MS LIDs patients showed only minor, nonsignificant reductions in striatal dopamine levels (2\%-3\%). In support of our PET findings, in the PD MM LIDs group, buspirone induced a significant $50 \%$ mean reduction of peak-dose LIDs (45-105 minutes after levodopa administration), while in the PD MS LIDs group, there was only a nonsignificant $25 \%$ mean reduction of LIDs.

These data indicate a stronger effect of the $5-\mathrm{HT}_{1 \mathrm{~A}}$ agonist buspirone in PD patients with milder LIDs. As PD advances and LIDs become severe, the loss of residual buffering capacity of the dopa- 

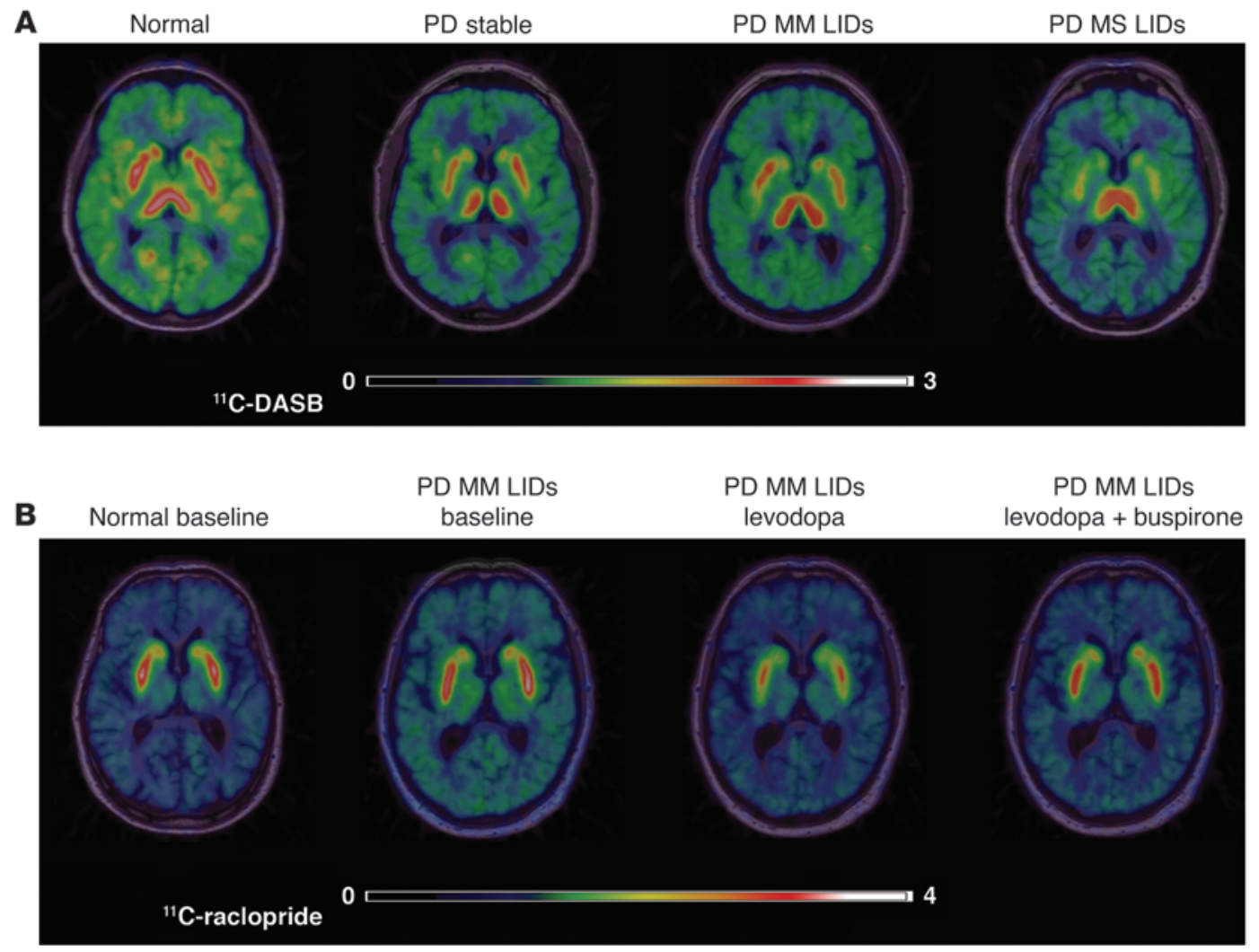

\section{Figure 6}

Examples of PET images, corregistered and fused with 1.5-Tesla MRI images at the level of dorsal basal ganglia, showing $B P_{N D}$ values for $P D$ patients and normal controls. (A) ${ }^{11} \mathrm{C}$-DASB PET images for a normal individual (62-year-old healthy male; caudate $\mathrm{BP}_{\mathrm{ND}}, 1.27$; putamen $\mathrm{BP} \mathrm{ND}_{\mathrm{N}}$,

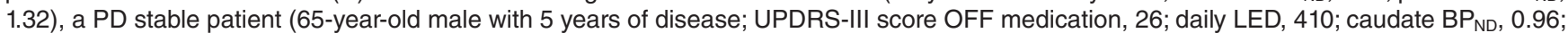
putamen $\mathrm{BP}_{\mathrm{ND}}, 1.14$ ), a PD MM LIDs patient (63-year-old male with 9 years of disease; UPDRS-III score OFF medication, 40; daily LED, 987; caudate $\mathrm{BP}_{\mathrm{ND}}, 0.94$; putamen $\mathrm{BP}_{\mathrm{ND}}, 1.17$ ), and a PD MS LIDs patient (61-year-old male with 13 years of disease; UPDRS score OFF medication, 51; daily LED, 1,025; caudate $\mathrm{BP}_{\mathrm{ND}}, 0.78$; putamen $\mathrm{BP}_{\mathrm{ND}}, 0.89$ ). (B) ${ }^{11} \mathrm{C}$-raclopride images for a normal individual (66-year-old healthy male; caudate $\mathrm{BP}_{\mathrm{ND}}$, 2.34; putamen $\mathrm{BP}_{\mathrm{ND}}$, 2.95) and for a PD MM LIDs patient (62-year-old male with 10 years of disease; UPDRS-III score OFF medication, 39; daily LED, 897), at baseline OFF medication (caudate $B P_{N D}, 2.16$; putamen $B P_{N D}, 2.87$ ), after levodopa administration (caudate $B P_{N D}$, 1.93; putamen $\mathrm{BP}_{\mathrm{ND}}, 2.18$ ), and after levodopa preceded by $0.35 \mathrm{mg} / \mathrm{kg}$ buspirone (caudate $\mathrm{BP}_{\mathrm{ND}}, 2.07$; putamen $\mathrm{BP}_{\mathrm{ND}}, 2.76$ ). Color bars show $\mathrm{BP} \mathrm{ND}_{\mathrm{ND}}$ range for ${ }^{11} \mathrm{C}$-DASB $\left(0-3\right.$ scale) and ${ }^{11} \mathrm{C}$-raclopride (0-4 scale).

minergic system leads to a greater but more aberrant contribution of serotonergic terminals in handling synaptic dopamine levels. Therefore, in cases with severe LIDs, higher doses of buspirone or use of more potent $5-\mathrm{HT}_{1 \mathrm{~A}}$ agonists are likely to be necessary in order to achieve similar suppression of LIDs. However, this raises the issue of whether this would be clinically meaningful. Although the high dose of buspirone used here did not affect levodopainduced improvement of motor function, $39 \%$ of $\mathrm{PD}$ patients experienced adverse events, albeit none were severe. It is possible that complete dampening of serotonergic terminal release may lead to significant adverse effects and also worsen the therapeutic effect of levodopa in the absence of any residual dopamine innervation.

2 previous large-scale, double-blind, randomized placebocontrolled trials, PADDY-1 and PADDY-2, failed to show an effect of the $5-\mathrm{HT}_{1 \mathrm{~A}}$ agonist sarizotan in relieving LIDs, despite positive results in preclinical and small-scale studies $(23,24)$. The largescale double-blind placebo-controlled trial that served as a foundation for these trials showed no significant benefit of sarizotan in alleviating LIDs against placebo, but chose patients that would fall in our PD MS LIDs group (25). It is possible, however, that these patients could have benefited from higher doses or more potent $5-\mathrm{HT}_{1 \mathrm{~A}}$ (and/or 5-HT $\mathrm{HB}_{1 \mathrm{~B}}$ ) agonists than buspirone and sarizotan. Another possibility is that other downstream mechanisms, such as glutamatergic overactivity, could play a more dominant role in generating severe dyskinesias, and therefore the combined use of an $5-\mathrm{HT}_{1 \mathrm{~A}}$ agonist and an NMDA antagonist may needed. The latter has been shown to reduce abnormal involuntary movement in animal models of PD at subthreshold doses $(19,26)$. Serotonergic mechanisms have been shown to play a role in the development of graft-induced dyskinesias $(27,28)$; however, there are distinct similarities and differences of how they are applied (29). Our present clinical observations were also in agreement with previous small, open-label clinical studies in PD patients with LIDs $(30,31)$.

The results of the present study provide proof of concept with respect to the involvement of serotonergic mechanisms in the development of LIDs. Currently, no medical treatment could be designated as efficacious for LIDs and anti-LIDs treatments, and phase III trials remain an ongoing challenge for investigators. Our present data support the development and use of potent $5-\mathrm{HT}_{1 \mathrm{~A}}$ agonists for the management of LIDs. 


\section{Methods}

Participants. We performed a series of PET and clinical assessments in PD patients recruited from UK university hospital clinics specialized in movement disorders (Table 1). After screening with the UPDRS-IV, PD patients were divided into PD stable $(n=12)$ and PD LIDs $(n=24)$ groups. By public advertisement, we also recruited age- and gender-matched healthy individuals who served as normal controls $(n=12)$ for PET imaging and clinical data comparisons, as well as for a double-blind randomized dose-finding trial with buspirone. For the dose-finding trial, 6 normal control patients each were assigned to receive $0.20 \mathrm{mg} / \mathrm{kg}(\sim 15 \mathrm{mg})$ or $0.35 \mathrm{mg} / \mathrm{kg}(\sim 30 \mathrm{mg})$ buspirone (Supplemental Table 1).

Procedures. The first part of the trial involved a dose-finding study with normal controls that was performed in order to explore whether buspirone influences $\mathrm{D}_{2}$ receptor availability with the dopaminergic system intact and to establish the adverse event profile with 2 different doses of the drug. The group of normal controls had, in a double-blind randomized order, an ${ }^{11} \mathrm{C}$-raclopride PET (a marker of dopamine $\mathrm{D}_{2}$ receptor availability) at baseline and again after a 0.20 or $0.35 \mathrm{mg} / \mathrm{kg}$ bolus dose of buspirone, given 75 minutes preceding the ${ }^{11} \mathrm{C}$-raclopride intravenous infusions. Normal controls also had clinical assessments, baseline ${ }^{11} \mathrm{C}$-DASB PET scan (a marker of SERT binding that provides an index of presynaptic serotonergic terminal integrity), and volumetric T1 MRI. The 2 normal control subgroups were matched for demographic characteristics (Supplemental Table 1).

PD patients withdrawn from medication for 18 hours had a levodopa challenge (levodopa 250/carbidopa 25) either alone or, on a separate occasion, preceded 15 minutes earlier by a dose of buspirone. The timings of drug administration were based on the known pharmacokinetics of a $30 \mathrm{mg}$ bolus dose of buspirone and of levodopa 250/carbidopa 25 designed to have the peak effect of levodopa coincide with $5-\mathrm{HT}_{1 \mathrm{~A}}$ blockade $(32,33)$. Clinical assessments were performed in a double-blind randomized fashion (Figure 1). LIDs were rated with AIMS, and motor performance was rated using UPDRS-III, every 15 minutes over a 150-minute period. Each AIMS assessment had duration preceding by 5 minutes and succeeding by 2.5 minutes each 15 -minute interval. The highest amplitude or frequency of dyskinesias on a $0-4$ scale was reported.

PD subjects received, in a randomized order: (a) an ${ }^{11} \mathrm{C}$-DASB PET when OFF medication, (b) $3{ }^{11} \mathrm{C}$-raclopride PET scans (1 OFF medication, 1 60 minutes after levodopa administration, and 160 minutes after levodopa administration preceded by buspirone 15 minutes earlier), and (c) a $1.5 \mathrm{~T}$ volumetric MRI scan (Figure 1).

All PET imaging was performed at the Cyclotron Building in Hammersmith Hospital, and the radiotracers were supplied by Hammersmith Imanet PLC. Details of PET and MRI scanners and PET data analysis have been previously described $(7,34)$. Briefly, all ${ }^{11} \mathrm{C}$-raclopride and ${ }^{11} \mathrm{C}$-DASB PET images were obtained with an ECAT EXACT HR+ scanner (Siemens). A transmission scan to measure tissue attenuation of radiation preceded the intravenous bolus injection of a mean dose of $250 \mathrm{MBq}{ }^{11} \mathrm{C}$-raclopride or $450 \mathrm{MBq}{ }^{11} \mathrm{C}$-DASB. Images were obtained as 20 time frames acquired over 60 minutes for ${ }^{11} \mathrm{C}$-raclopride and as 28 time frames acquired over 90 minutes for ${ }^{11} \mathrm{C}$-DASB.

Whole blood samples from all subjects were acquired in order to genotype the functional polymorphisms of the SERT gene (LPR and VNTR), and meteorological data for the periods of ${ }^{11} \mathrm{C}$-DASB PET scanning were recorded to explore potential confounding factors of gene variation, weather, and seasonal changes on ${ }^{11} \mathrm{C}$-DASB binding, as previously described (7). We found no influence of genetic polymorphisms, temperate seasons, sunshine, humidity, and temperature on our serotonergic results (Supplemental Methods).

All PET images were corrected for motion artifacts using frame-by-frame realignment. Parametric images of ${ }^{11} \mathrm{C}$-raclopride $\mathrm{BP}_{\mathrm{ND}}$ were generated from the dynamic ${ }^{11} \mathrm{C}$-raclopride scans using a basis function implemen- tation of the simplified reference tissue model, with the cerebellum as the reference tissue for nonspecific binding (35), and corregistered and resliced to the corresponding volumetric T1-weighted MRI. For ${ }^{11} \mathrm{C}$-DASB PET images, the input function was derived from the nonspecific tracer-binding signal in the posterior cerebellar gray matter cortex, avoiding inclusion of the vermis (36). Volume of distribution ratios (VDR) were computed for regions of interest (ROIs) with the graphical analysis method of Logan (37), and $\mathrm{BP}_{\mathrm{ND}}$ was calculated as VDR - 1 (38). ROIs were traced on the individual corregistered MRIs, then used to sample the parametric PET images. Percent changes from the practically defined OFF-medication phase for ROIs ${ }^{11} \mathrm{C}$-raclopride $\mathrm{BP}$ ND after levodopa administration, with and without buspirone pretreatment, were also calculated (see Supplemental Methods for details of PET analysis). Clinical assessments and imaging analyses were blinded to treatment type.

Statistics. Statistical analysis and graph illustration were performed with GraphPad Prism (version 6.0c) and SPSS (version 22) for MAC OS X. For all variables, variance homogeneity and Gaussianity were tested with Bartlett and Kolmogorov-Smirnov tests, and we proceeded with parametric tests, as our PET and clinical data were normally distributed. For the dose defining study in normal controls, we compared ${ }^{11} \mathrm{C}$-raclopride $\mathrm{BP}_{\mathrm{ND}}$ at baseline (OFF medication) and after challenge with buspirone, and we computed 2-tailed $P$ values with paired $t$ tests (Supplemental Figure 1 and Supplemental Tables 1 and 2). General clinical characteristics among normal control, PD stable, and PD LIDs groups were compared for $F$ and $P$ values with ordinary 1-way ANOVA followed by Brown-Forsythe and Bartlett's tests. When ANOVA $P$ values were significant, we calculated between-group $P$ values followed by Bonferroni's multiple-comparisons test (Table 1). Specific PD clinical characteristics were compared between the PD MM LIDs and PD MS LIDs subgroups calculating 2-tailed $P$ values with unpaired $t$ tests (Table 2).

Since we identified significant differences in some of the clinical characteristics between the PD stable and PD LIDs groups, we wanted to explore whether these would affect our planned comparisons and thus included them as covariates in analysis. We included 3 possible confounders in a multiple linear regression analysis and concluded that PD duration $\left(F_{(6,29)}=0.3487\right.$; $P>0.1)$, PD medication duration $\left(F_{(6,29)}=0.3431 ; P>0.1\right)$, and lifetime levodopa equivalent dose $\left(\operatorname{LED} ; F_{(6,29)}=0.3192 ; P>0.1\right)$ did not influence the PET $\left({ }^{11} \mathrm{C}\right.$-raclopride $\mathrm{BP}_{\mathrm{ND}}$ and ${ }^{11} \mathrm{C}$-DASB $\left.\mathrm{BP} \mathrm{ND}_{\mathrm{ND}}\right)$ data in these $\mathrm{PD}$ patients.

We calculated 2-tailed $P$ values comparing caudate and putamen ${ }^{11} \mathrm{C}$-DASB BP ${ }_{\mathrm{ND}}$ between the PD stable and PD LIDs groups using unpaired $t$ tests (Figure 2A and Supplemental Table 5). In post-hoc analysis, $F$ and $P$ values for ${ }^{11} \mathrm{C}$-DASB BP $\mathrm{ND}_{\mathrm{ND}}$ among the normal control, PD stable, PD MM LIDs, and PD MS LIDs groups were computed with ordinary 1-way ANOVA followed by Brown-Forsythe and Bartlett's tests, as well as Bonferroni's multiple-comparisons test (Figure 4A and Supplemental Table 9).

We assessed the effect of medication (OFF medication, levodopa alone, levodopa with buspirone pretreatment) in caudate and putamen ${ }^{11} \mathrm{C}$-raclopride $\mathrm{BP}_{\mathrm{ND}}$ using repeated-measures ANOVA with the Greenhouse-Geisser correction ( $F$ and $P$ values) in the PD stable (Figure $2 \mathrm{~B}$ and Supplemental Table 6), PD LIDs (Figure 2C and Supplemental Table 7), PD MM LIDs (Figure 4B and Supplemental Table 10), and PD MS LIDs (Figure 4C and Supplemental Table 11) groups. If ANOVA $P$ values were significant, we carried out between-condition comparisons, calculating $P$ values following Bonferroni's multiple-comparisons test.

We computed $F$ and $P$ values and analyzed the effect of time ( $0-150$ minutes) and treatment (levodopa alone vs. levodopa with buspirone pretreatment) in AIMS and UPDRS-III scores using 2-way ANOVA (2 factors: treatment and time) with repeated measures in the PD LIDs (Figure 2, D and E), PD MM LIDs (Figure 4, D and F), and PD MM LIDs (Figure 4, E and G) groups. Any significant interaction was further analyzed for time-treatment significance using Bonferroni's multiple-comparisons test. 
We interrogated correlations between PET and clinical data using Pearson $r$. We investigated (a) whether percent change in caudate and putamen ${ }^{11} \mathrm{C}$-raclopride $\mathrm{BP}_{\mathrm{ND}}$ correlated with maximum and average AIMS scores after levodopa administration in the PD LIDs group (Supplemental Figure 2); (b) whether caudate and putamen ${ }^{11} \mathrm{C}-\mathrm{DASB} B \mathrm{P}_{\mathrm{ND}}$ was associated with percent change in caudate and putamen ${ }^{11} \mathrm{C}$-raclopride $\mathrm{BP} \mathrm{ND}_{\mathrm{ND}}$ after buspirone pretreatment (Figure $2 \mathrm{~F}$ ); (c) whether caudate and putamen ${ }^{11} \mathrm{C}-\mathrm{DASB} B \mathrm{PP}_{\mathrm{ND}}$ correlated with maximum and average AIMS scores after levodopa administration in the PD LIDs group (Figure 5A and Supplemental Figures 3 and 4); and (d) whether improvements in maximum and average AIMS correlated with percent change in caudate and putamen ${ }^{11} \mathrm{C}$-raclopride $\mathrm{BP}_{\mathrm{ND}}$ (corrected for ${ }^{11} \mathrm{C}$-DASB $\mathrm{BP} \mathrm{ND}_{\mathrm{ND}}$ ) after buspirone pretreatment in the PD LIDs group (Figure 5B). After this step, we applied corrections for multiple comparisons for each set of correlations using PPLot (version 1.0) in Matlab (39). PPLot combines the graphical estimation of the number of "true" null hypotheses in the set of correlations with the Hochberg multiple-comparison correction.

All data are presented as mean \pm SD, and the level $\alpha$ was set for all comparisons at $P<0.05$, corrected.

1. Lees AJ, Shaw KM, Stern GM. "Off period" dystonia and "on period" choreoathetosis in levodopatreated patients with Parkinson's disease. Lancet. 1977;2(8046):1034.

2. de la Fuente-Fernández R, et al. Levodopa-induced changes in synaptic dopamine levels increase with progression of Parkinson's disease: implications for dyskinesias. Brain. 2004;127(12):2747-2754.

3. Ng KY, Chase TN, Colburn RW, Kopin IJ. L-Dopainduced release of cerebral monoamines. Science. 1970;170(3953):76-77.

4. Ng KY, Colburn RW, Kopin IJ. Effects of L-dopa on efflux of cerebral monoamines from synaptosomes. Nature. 1971;230(5292):331-332.

5. Tanaka H, Kannari K, Maeda T, Tomiyama M, Suda T, Matsunaga M. Role of serotonergic neurons in L-DOPA-derived extracellular dopamine in the striatum of 6-OHDA-lesioned rats. Neuroreport. 1999;10(3):631-634.

6. Kish SJ, et al. Preferential loss of serotonin markers in caudate versus putamen in Parkinson's disease. Brain. 2008;131(1):120-131.

7. Politis M, et al. Staging of serotonergic dysfunction in Parkinson's disease: an in vivo 11C-DASB PET study. Neurobiol Dis. 2010;40(1):216-221.

8. Schmidt CJ, Lovenberg W. In vitro demonstration of dopamine uptake by neostriatal serotonergic neurons of the rat. Neurosci Lett. 1985;59(1):9-14.

9. Saldaña SN, Barker EL. Temperature and 3,4-methylenedioxymethamphetamine alter human serotonin transporter-mediated dopamine uptake. Neurosci Lett. 2004;354(3):209-212.

10. Maeda T, Nagata K, Yoshida Y, Kannari K. Serotonergic hyperinnervation into the dopaminergic denervated striatum compensates for dopamine conversion from exogenously administered l-DOPA. Brain Res. 2005;1046(1-2):230-233.

11. Kannari K, Shen H, Arai A, Tomiyama M, Baba M. Reuptake of L-DOPA-derived extracellular dopamine in the striatum with dopaminergic denervation via serotonin transporters. Neurosci Lett. 2006;402(1-2):62-65.

12. Carta M, Carlsson T, Kirik D, Björklund A. Dopamine released from 5-HT terminals is the cause of L-DOPA-induced dyskinesia in parkinsonian rats. Brain. 2007;130(7):1819-1833.

13. Eskow KL, Gupta V, Alam S, Park JY, Bishop C. The partial 5-HT(1A) agonist buspirone reduces the expression and development of 1-DOPA-induced dyskinesia in rats and improves 1-DOPA efficacy.

Study approval. The study was approved by the local ethics committees, and written informed consent was obtained from each participant.

\section{Acknowledgments}

We thank the patients and their families for the participation and the Medical Research Council (United Kingdom) for the workspace. We also thank the radiographers of Hammersmith Imanet Ltd. for their help. The funding source of this study was The Michael J. Fox Foundation for Parkinson's Research (P14104).

Received for publication June 18, 2013, and accepted in revised form December 5, 2013.

Address correspondence to: Marios Politis, Neurodegeneration Imaging Group, Department of Clinical Neuroscience, King's College London, De Crespigny Park, London SE5 8AF, United Kingdom. Phone: 44.0207.848.5682; Fax: 44.0207.848.0988; E-mail: marios.politis@kcl.ac.uk.

Pharmacol Biochem Behav. 2007;87(3):306-314

14. Dekundy A, Lundblad M, Danysz W, Cenci MA Modulation of L-DOPA-induced abnormal involuntary movements by clinically tested compounds: further validation of the rat dyskinesia model. Behav Brain Res. 2007;179(1):76-89.

15. Muñoz A, et al. Combined 5-HT1A and 5-HT1B receptor agonists for the treatment of L-DOPAinduced dyskinesia. Brain. 2008;131(12):3380-3394.

16. Dupre KB, Eskow KL, Barnum CJ, Bishop C. Striatal 5-HT1A receptor stimulation reduces D1 receptor-induced dyskinesia and improves movement in the hemiparkinsonian rat. Neuropharmacology. 2008;55(8):1321-1328.

17. Lindgren HS, Andersson DR, Lagerkvist S, Nissbrandt $\mathrm{H}$, Cenci MA. L-DOPA-induced dopamine efflux in the striatum and the substantia nigra in a rat model of Parkinson's disease: temporal and quantitative relationship to the expression of dyskinesia. J Neurochem. 2010;112(6):1465-1476.

18. Nahimi A, et al. Serotonergic modulation of receptor occupancy in rats treated with L-DOPA after unilateral 6-OHDA lesioning. J Neurochem. 2012;120(5):806-817.

19. Bezard E, et al. Study of the antidyskinetic effect of eltoprazine in animal models of levodopa-induced dyskinesia. Mov Disord. 2013;28(8):1088-1096.

20. Khan NL, et al. Clinical and subclinical dopaminergic dysfunction in PARK6-linked parkinsonism: an 18F-dopa PET study. Ann Neurol. 2002;52(6):849-853.

21. de la Fuente-Fernández R, et al. Evidence for impaired presynaptic dopamine function in parkinsonian patients with motor fluctuations. J Neural Transm. 2000;107(1):49-57.

22. Rylander D, et al. Maladaptive plasticity of serotonin axon terminals in levodopa-induced dyskinesia. Ann Neurol. 2010;68(5):619-628.

23. Bibbiani F, Oh JD, Chase TN. Serotonin 5-HT1A agonist improves motor complications in rodent and primate parkinsonian models. Neurology. 2001;57(10):1829-1834.

24. Bara-Jimenez W, et al. Effects of serotonin 5-HT1A agonist in advanced Parkinson's disease. Mov Disord. 2005;20(8):932-936.

25. Goetz CG, et al. Sarizotan as a treatment for dyskinesias in Parkinson's disease: a double-blind placebo-controlled trial. Mov Disord. 2007;22(2):179-186.

26. Dupre KB, et al. Effects of coincident 5-HT1A receptor stimulation and NMDA receptor antagonism on L-DOPA-induced dyskinesia and rota- tional behaviors in the hemi-parkinsonian rat. Psychopharmacology. 2008;199(1):99-108.

27. Politis M, et al. Serotonergic neurons mediate dyskinesia side effects in Parkinson's patients with neural transplants. Sci Transl Med. 2010;2(38):38ra46.

28. Politis M, et al. Graft-induced dyskinesias in Parkinson's disease: High striatal serotonin/dopamine transporter ratio. Mov Disord. 2011;26(11):1997-2003.

29. Politis M. Dyskinesias after neural transplantation in Parkinson's disease: what do we know and what is next? BMC Med. 2010;8:80

30. Kleedorfer B, Lees AJ, Stern GM. Buspirone in the treatment of levodopa induced dyskinesias. J Neurol Neurosurg Psychiatry. 1991;54(4):376-377.

31. Bonifati V, Fabrizio E, Cipriani R, Vanacore N, Meco G. Buspirone in levodopa-induced dyskinesias. Clin Neuropharmacol. 1994;17(1):73-82.

32. Rainero I, et al. Peripheral pharmacokinetic parameters of levodopa/carbidopa and the on-off phenomenon in parkinsonian patients. Ital J Neurol Sci. 1988;9(3):225-259.

33. Lamberg TS, Kivistö KT, Neuvonen PJ. Concentrations and effects of buspirone are considerably reduced by rifampicin. Br J Clin Pharmacol. 1998; 45(4):381-385

34. Politis M, Pavese N, Tai YF, Tabrizi SJ, Barker RA, Piccini P. Hypothalamic involvement in Huntington's disease: an in vivo PET study. Brain. 2008; 131(11):2860-2869.

35. Gunn RN, Lammertsma AA, Hume SP, Cunningham VJ. Parametric imaging of ligand-receptor binding in PET using a simplified reference region model. Neuroimage. 1997;6(4):279-287.

36. Kish SJ, et al. Regional distribution of serotonin transporter protein in postmortem human brain: is the cerebellum a SERT-free brain region? $\mathrm{Nucl}$ Med Biol. 2005;32(2):123-128.

37. Logan J, Fowler JS, Volkow ND, Wang GJ, Ding YS, Alexoff DL. Distribution volume ratios without blood sampling from graphical analysis of PET data. J Cereb Blood Flow Metab. 1996;16(5):834-840.

38. Ginovart N, Wilson AA, Meyer JH, Hussey D, Houle S. Positron emission tomography quantification of [(11)C]-DASB binding to the human serotonin transporter: modeling strategies. J Cereb Blood Flow Metab. 2001;21(11):1342-1353.

39. Turkheimer FE, Smith CB, Schmidt K. Estimation of the number of "true" null hypotheses in multivariate analysis of neuroimaging data. Neuroimage. 2001;13(5):920-930. 